\title{
EMISSION OF POLYCYCLIC AROMATIC HYDROCARBONS IN INDOOR AIR DURING BURNING OF MOSQUITO COILS AND THEIR IMPACTS ON THE LIVERS OF THE EXPOSED ALBINO RATS
}

\author{
Safaa E. Nassar ${ }^{1 *}$; Eman I. M. Ismail ${ }^{2}$ \\ ${ }^{1}$ Zoology Department, Faculty of Science, Zagazig University, Zagazig, Sharqia, Egypt \\ ${ }^{2}$ Animal Health Research Institute (AHRI), Agricultural Research Center (ARC), Zagazig, \\ Sharqia, Egypt
}

Article History:

Received: 5 March 2021

Revised: 31 March 2021

Accepted: 31 March 2021

Published Online:

7 April 2021

\section{Keywords:}

Albino rats

Hepatotoxicity

Mosquito coils

PAHs

Particulate matter

*Correspondence:

Safaa Nassar

Zoology Department

Faculty of Science

Zagazig University

Zagazig, Sharqia, Egypt

E-mail:

safaaezat@zu.edu.eg

\begin{abstract}
The indoor burning of mosquito coils (MCs) results in generation of particulate matter (PM) and polycyclic aromatic hydrocarbons (PAHs) in an uncontrolled manner. These emissions pose a serious public health hazards and ecological challenges. Therefore, in the present study the concentrations of PM and its content of PAHs during the indoor application of MCs were determined. In addition, some serum biochemical alternations and histological changes in the liver tissues of male albino rats (Rattus norvegicus) exposed to MC smoke for 8 hours per day over 3-12 weeks were investigated. The concentrations of PM and PAHs in indoor air environment ranged from 210 to $2050 \mu \mathrm{g} / \mathrm{m}^{3}$ and from 2.57 to $56.76 \mu \mathrm{g} / \mathrm{m}^{3}$, respectively. In addition, the mean concentration of emission of benzo[a]pyrene (the most carcinogenic PAH) was $4.19 \pm$ $1.10 \mu \mathrm{g} / \mathrm{m}^{3}$. Serum aminotransferases and alkaline phosphatase activities, as well as serum total protein, triacylglycerol, cholesterol, and low-density lipoprotein levels, were increased significantly in PAHs-exposed rats compared with the control rats $(P<0.05-P<0.001, \mathrm{n}=5)$. The significant elevation in these parameters was dependent on the duration of exposure. The histological examination of the liver tissues of PAHs-exposed rats showed marked degenerative, vascular and sinusoidal dilatation, and early necrotic changes in hepatocytes alongside fatty steatosis. In conclusion, prolonged exposure to PAHs emitted particles during burning of MCs could cause hepatotoxicity and dyslipidemia. Thus, it is recommended to use MCs only outdoors to reduce their health risk.
\end{abstract}

\section{INTRODUCTION}

Mosquito coils (MCs) are widely used in South America, Asia, and Africa by low income communities as a low cost method for mosquito-repelling ${ }^{[1]}$. The repelling of mosquitoes is an effective way to decrease mosquito-borne pathogenic diseases such as filariasis, malaria, Nile virus, dengue, and yellow fever ${ }^{[2]}$. In recent decades MC usage has increased and the annual worldwide consumption was estimated to be 32 billion pieces as at the year 2000, pollutant 
concentration from their emission is greater than the World Health Organization (WHO) standards ${ }^{[3]}$.

The MC is made up of insecticides like pyrethroids, organic fillers, dyes, and other additives that are able to smolder well ${ }^{[4]}$. Beside pyrethroids that considered the main active ingredients of most $\mathrm{MCs}$, accounting for approximately $0.3-0.4 \%$ of MC mass ${ }^{[5]}$, the filler make up $99 \%$ of $\mathrm{MC}$ including wood dust or coconut shell flour and other compounds ${ }^{[6]}$.

Burning of MC in indoor environment is considered as potent indoor air pollution. Although it is reported that MC burning causes evaporation of insecticides that are of low toxicity to humans, a large amount of sub-micrometer particles, metal fumes, and gaseous pollutants such as polycyclic aromatic hydrocarbons (PAHs) are also emitted in an uncontrolled manner upon the incomplete combustion ${ }^{[7,8]}$. Particulate matter (PM) released by burning one MC equal to those emitted upon burning 75137 cigarettes, and formaldehyde will be released as high as 51 cigarettes is burned ${ }^{[4]}$.

Since, consumers usually use MC overnight in sleeping rooms daily especially during summer season, this long term of exposure raising questions to the potential toxicological influence of PAHs of $\mathrm{MC}$ smoke on human health. Exposure to MC smoke has been documented to cause clinical symptoms such as asthma and persistent wheeze ${ }^{[9]}$. Due to their lipophilicity, PAHs have high residence and low clearance in different organs of rats such as the brain, liver, and lung ${ }^{[10]}$. As the liver is the main metabolic organ of PAHs, inhaled benzo $[a]$ pyrene produces reactive oxygen species (ROS) in the liver, which lead directly to its hepatotoxicity ${ }^{[11]}$.

Up to now, most studies have paid greater attention to respiratory toxicity of inhaled PAHs, so that its hepatotoxic effects are still unclear. So far, this study aimed to monitor indoor air concentrations of PAHs and PM during the application of MC and to investigate some serum biochemical alternations alongside histological changes of the liver tissues of albino rats after inhalation of MC smoke.

\section{MATERIAL AND METHODS Mosquito coil description}

Commercial available LAOJUN MCs (Jinjiang Laojun Chemical Co., Ltd, Jinjiang City, Fujian Province, China) were purchased from a local supermarket in Zagazig city (Sharqia, Egypt). The studied MC contained dimefluthrin $0.2 \%$ (weight/weight) of as an active ingredient, carbon powder $64 \%$, wooden powder $25 \%$, corn starch $9.4 \%$, and kerosene $0.52 \%$. The repellent MC is black, typically spiral in shape, and measuring $14 \mathrm{~cm}$ in diameter, $85 \mathrm{~cm}$ in length, and weighing approximately $14 \mathrm{~g}$.

\section{Air sampling and analysis}

Air sampling was conducted in a room size of $48 \mathrm{~m}^{3}$, with a window and one door that allowed air exchange and provided day light diffusion. One MC was applied per night, as each MC is expected to burn for 8 hours. The MC was heated and was placed on the floor at a distance of $30 \mathrm{~cm}$ from the cages.

During the burning period of the MC (from 10:00 pm to 6:00 am), indoor air was sampled using a personal samplers with a constant flow motor pump of a flow rate $1.0 \mathrm{~L} /$ minute. Two samplers were placed parallel at the height of $30 \mathrm{~cm}$ from the floor and beside the animal cages. Three to four samples were taken monthly through the experiment, using $25 \mathrm{~mm}$ desiccated glass fiber filters (GFF, Whatman, Maidstone, UK) weighed on an electrobalance before and after sampling to measure the total suspended particulate matter (TPM). The GFF in the sampler served to collect PAHs in the particle phases. Blank Air samples were taken from the room before MC application, to ensure that there was no pollution prior to the experiment. At the end of the MC application, the GFF was removed from the sampler, wrapped individually with clean aluminum foil, sealed in plastic bags, transferred back to the 
laboratory, and stored at low temperature until analysis. Seven glass fiber filters were extracted according method described by Sanderson and Farant ${ }^{[12]}$ with $150 \mathrm{~mL}$ dichloromethane individually for 16 hours at $75^{\circ} \mathrm{C}$. The extracts were analyzed with high performance liquid chromatography at Central Laboratories Network, National Research Centre, Giza, Egypt.

\section{Experimental animals}

A total of 20 male albino rats (Rattus norvegicus) weighing between (150-180 g), purchased from the farm on the Faculty of Veterinary Medicine at Zagazig University, were used in this study. The animals were housed in cages and acclimatized for two weeks under standard laboratory conditions, with ad libitum access of food and water. Rats were randomly divided into four groups and each group comprised of five animals. Control group (group 1) inhaled fresh air, while the exposed groups were kept in a separate room, where they allowed to inhale MC smoke daily at night for 8 hours (the average period of time that human sleep at night) either for 3 weeks (group 2), for 6 weeks (group 3), or for 12 weeks (group 4).

\section{Biochemical analysis}

At the end of each exposure period, all the animals were euthanized with chloroform in desiccators and blood samples were collected by cardiac puncture. Blood samples were immediately transferred into clean tubes, kept to coagulate, and then centrifuged to separate serum that stored at $-20^{\circ} \mathrm{C}$ for biochemical analysis. Serum aspartate aminotransferase (AST) and alanine aminotransferase (ALT) activities were measured according to Reitman and Frankel ${ }^{[13]}$ method, while alkaline phosphatase (ALP) activity was measured according to Tietz ${ }^{[14]}$ method. Total serum protein, triacylglycerol (TG), total cholesterol, and low-density lipoprotein (LDL) concentrations were determined by Doumas et al. ${ }^{[15]}$, Fossati and Prencips ${ }^{[16]}$, Artiss and Zak ${ }^{[17]}$, and Wieland and Seidel ${ }^{[18]}$ methods, respectively.

\section{Histological analysis}

Liver tissues were quickly collected from the control and exposed animals, fixed in formalin solution (10\%), then dehydrated and embedded in paraffin wax. Sections were cut at 3-4 $\mu \mathrm{m}$ in thickness, and deparaffinized tissues were stained with hematoxylin and eosin ${ }^{[19]}$. Stained sections were examined for inflammation, degenerations, and any other pathologic lesions in the tissues by using the light microscope.

\section{Statistical analysis}

Data were analyzed by a one-way analysis of variance (ANOVA) and post-hoc test using of software SPSS (version 16.0). Results were presented as mean \pm standard error of mean, with value of $P<0.05$ defined as statistically significant.

\section{RESULTS}

\section{Concentrations of PAHs and PM in indoor air}

Twelve of PAHs (indeno[1,2,3-cd]pyrene, naphthalene, fluoranthene, phenanthrene, anthracene, fluorene, acenaphthene, pyrene, benzo[b]fluoranthene, benzo[ $k]$ fluoranthene, benz $[a]$ anthracene and benzo $[a]$ pyrene), which exist in the Priority Chemical List of Environmental Protection Agency (EPA; Washington, DC, USA), were quantified in 7 samples of glass filters containing PM generated during application of MC in indoor environment. Table " 1 " showed the average concentration of PM and individual PAHs found in emissions of the MC. PAHs concentrations in the emissions ranged from 2.57-56.76 $\mu \mathrm{g} / \mathrm{m}^{3}$. The mean concentrations of naphthalene and pyrene were found high $(50.64 \pm 1.23$ and $39.14 \pm 1.45 \mu \mathrm{g} / \mathrm{m}^{3}$, respectively), comprising $24-19 \%$, respectively of total emissions. The mean concentrations of benzo[ $k]$ fluoranthene and benzo $[a]$ pyrene were found to be less $(3.21 \pm 0.72,4.19 \pm$ $0.53 \mu \mathrm{g} / \mathrm{m}^{3}$, respectively). Overall, the order of twelve PAHs concentration in $\mathrm{PM}$ in indoor air was found to be naphthalene > pyrene > acenaphthene 
$>$ indeno[1,2,3-cd]pyrene > fluoranthene $>$ benz $[a]$ anthracene > fluorine > phenanthrene $>$ anthracene $>$ benzo $[b]-$ fluoranthene > benzo $[a]$ pyrene $>$ benzo $[k]-$ fluoranthene. However, the average concentration of PM in indoor air environment for 22 glass filters collected during the burning of $\mathrm{MC}$ ranged from $210-2050 \mu \mathrm{g} / \mathrm{m}^{3}$ with mean concentration of $1231.25 \mu \mathrm{g} / \mathrm{m}^{3}$ (Table 1 ).

Table 1: Concentrations of PAHs and TPM $\left(\mu \mathrm{g} / \mathrm{m}^{3}\right)$ in indoor air during the burning of mosquito coil for 8 hours.

\begin{tabular}{lccrr}
\hline \multicolumn{1}{c}{ Pollutants } & $\begin{array}{c}\text { IARC } \\
\text { classification }\end{array}$ & $\begin{array}{c}\text { Mean } \pm \text { SEM } \\
\left(\mu \mathrm{g} / \mathrm{m}^{3}\right)\end{array}$ & Minimum & Maximum \\
\hline TPM $(\mathrm{n}=22)$ & Group 3 & $1231.25 \pm 171.84$ & 210.00 & 2050.00 \\
Naphthalene & Group 3 & $50.64 \pm 1.23$ & 47.02 & 56.76 \\
Fluoranthene & Group 3 & $22.81 \pm 1.04$ & 20.36 & 28.09 \\
Phenanthrene & Group 3 & $7.25 \pm 1.49$ & 2.57 & 12.50 \\
Anthracene & Group 3 & $6.72 \pm 0.83$ & 4.14 & 9.22 \\
Fluorene & Group 3 & $6.79 \pm 0.92$ & 3.55 & 9.63 \\
Acenaphthene & Group 3 & $26.55 \pm 1.43$ & 22.01 & 33.43 \\
Pyrene & Group 3 & $39.14 \pm 1.45$ & 35.32 & 45.33 \\
Benz[ $a$ ]anthracene & Group 2B & $13.20 \pm 1.04$ & 9.76 & 17.10 \\
Benzo[ $b]$ fluoranthene & Group 2B & $5.98 \pm 0.97$ & 3.11 & 9.01 \\
Benzo[ $k]$ fluoranthene & Group 2B & $3.21 \pm 0.72$ & 1.11 & 6.23 \\
Benzo[ $a$ ]pyrene & Group 1 & $4.19 \pm 0.53$ & 2.87 & 6.15 \\
Indeno[1,2,3- $c d]$ pyrene & Group 2B & $24.08 \pm 1.41$ & 21.11 & 31.33 \\
$\Sigma$ PAH12 $(\mathrm{n}=7)$ & & $210.56 \pm 13.06$ & & \\
\hline
\end{tabular}

No PAHs were detected in blank samples. IARC classification: group 1, carcinogenic to humans; group 2B, possibly carcinogenic to humans; group 3, not classifiable as to its carcinogenicity to humans. $\Sigma$ PAH: sum of all PAHs; n: number of samples; PAHs: polycyclic aromatic hydrocarbons; SEM: standard error of mean; TPM: total particulate matter.

\section{Biochemical changes in sera of PAHs- exposed rats}

The data presented in Table "2" revealed alternations in some biochemical parameters in serum of albino rats after inhalation of PAHs during application of MC. The activities of serum ALT, AST, and ALP (the enzymatic markers for tissue-injury) showed significant increases in all the exposed groups when compared with the control group. At the exposure period of 12 weeks, their activities were elevated (at $P<0.001$ ) by $55 \%, 40 \%$, and $53 \%$, respectively, as compared with the control group. Lipid profile test revealed a statistically significant increase $(P<0.01-P<0.001)$ in the cholesterol and TG levels in all groups exposed to PAHs.
However, LDL levels increased significantly $(P<0.05-P<0.01)$ in exposed groups for 3,6 , and 12 weeks with $25 \%, 12 \%$, and $24 \%$, respectively when compared with the control group. However, protein levels showed a significant increase in all the exposed groups when compared with the control group. At the exposure period of 12 weeks, its level was elevated (at $P<0.001$ ) by $38 \%$ as compared with the control group.

\section{Histological alterations in the livers of PAHs-exposed rats}

Liver tissues of the rats after inhalation of PAHs during burning of MC showed different degrees of histological changes as 
compare to the control group. Examination of serial sections of liver revealed normal hepatic parenchyma with preserved lobular pattern, portal triads, and associated structures (portal vein, hepatic artery, hepatic vein, bile ductules, and lymphatics) in the control group that not exposed to PAHs (Figure 1a). Central vein sinusoids and hepatic cords were also apparently normal. In addition, hepatic lobules were separated by fine fibrous stromal connective tissue (Figure 1a).

Table 2: Some biochemical parameters in serum of rats after inhalation of PAHs during indoors burning of mosquito coils.

\begin{tabular}{lcccc}
\hline & \multirow{2}{*}{ Control } & \multicolumn{3}{c}{ Exposure duration to PAHs } \\
\cline { 3 - 5 } & & 3 weeks & 6 weeks & 12 weeks \\
\cline { 2 - 5 } ALT (U/L) & $35.00 \pm 1.47$ & $40.75 \pm 1.49 *$ & $44.25 \pm 2.06 * *$ & $54.25 \pm 2.29 * * *$ \\
AST (U/L) & $146.00 \pm 1.29$ & $165.75 \pm 8.56 *$ & $173.00 \pm 6.42 *$ & $205.25 \pm 7.71 * * *$ \\
ALP (U/L) & $195.00 \pm 9.63$ & $230.50 \pm 4.73 *$ & $263.00 \pm 11.81 * * *$ & $298.25 \pm 7.11 * * *$ \\
Cholesterol (mg/dL) & $48.25 \pm 1.49$ & $76.00 \pm 4.53 * * *$ & $67.75 \pm 2.49 * *$ & $81.00 \pm 3.79 * * *$ \\
TG (mg/dL) & $106.00 \pm 3.37$ & $169.25 \pm 4.19 * * *$ & $146.00 \pm 6.87 * * *$ & $178.50 \pm 3.68 * * *$ \\
LDL $(\mathrm{mg} / \mathrm{dL})$ & $28.75 \pm 1.25$ & $36.00 \pm 0.82 * *$ & $32.25 \pm 0.95 *$ & $35.75 \pm 1.65 * * *$ \\
Protein $(\mathrm{g} / \mathrm{dL})$ & $5.96 \pm 0.15$ & $6.90 \pm 0.31 *$ & $6.98 \pm 0.19 *$ & $8.20 \pm 0.32 * * *$ \\
\hline
\end{tabular}

Values were expressed as mean \pm standard error of mean $(n=5)$. Significance relative to the control group was set at ${ }^{*} P<0.05 ;{ }^{* *} P<0.01$, and ${ }^{* * * *} P<0.001$. ALT: alanine aminotransferase, AST: aspartate aminotransferase; ALP: alkaline phosphatase; TG: triacylglycerol; LDL: lowdensity lipoprotein

On the other hand, serial sections from liver of group 2 ( 3 weeks exposure to PAHs) showed moderately congested portal veins and dilated hepatic sinusoids (Figure 1b). The portal triads showed moderate biliary proliferation and mild round cells infiltration (lymphocytes and plasma cells). The hepatocytes suffered marked degenerative changes; cloudy swelling, hydropic degeneration and/or vacuolations, beside apoptotic and early necrotic changes in a variable number of cells (Figure 1b).

Liver tissues of group 3 (6 weeks exposure to PAHs) had remarkable portal vascular and sinusoidal dilatation, endothelial swelling, edema, biliary proliferation, and round cells infiltration (Figure 1c). The hepatocytes showed marked degenerative and early necrotic changes beside fatty steatosis (Figure 1c).

Liver tissues of group 4 (12 weeks exposure to PAHs) had marked portal round cells infiltration, vascular and sinusoidal dilatation, arteriolar wall hyalinization, and endothelial swelling beside characteristic hepatocellular hydropic degeneration, steatosis, and early necrosis (Figure 1d).

\section{DISCUSSION}

The MC is generally known as an effective mosquito repellent. The indoor burning of $\mathrm{MC}$ results in generation of large quantities of submicrometer particles and gaseous contaminants. These submicrometer particles may be coated with a broad range of organic compounds; some of these compounds are carcinogens or probably carcinogens such as PAHs, which produced in an uncontrolled manner through the incomplete combustion of MC base materials ${ }^{[8]}$.

The PM concentrations measured during the burning of MC for 8 hours in the current study ranged from $210-2050 \mu \mathrm{g} / \mathrm{m}^{3}$, these levels exceeded the Indoor Air Quality 
Objectives (IAQO) of 8-hour average good class concentration of $\mathrm{PM}\left(0.18 \mathrm{mg} / \mathrm{m}^{3}\right)$ stated by $\mathrm{WHO}^{[20]}$. They are also higher than those measured by Dubey et al. ${ }^{[7]}$ who stated that the emission of PM of the tested MCs were $76.8-118.3 \pm 31 \mu \mathrm{g} / \mathrm{m}^{3}$, respectively, but still lower than PM levels reported in literatures. Lee and Wang ${ }^{[21]}$ stated average PM10 concentrations for MCs ranged from 10 to $10530 \mu \mathrm{g} / \mathrm{m}^{3}$. However, the chamber concentrations of PM produced from the combustion of two Malaysianbrand MCs according to Liu et al. ${ }^{[22]}$ were $363 \pm 12$ and $365 \pm 19 \mathrm{mg} / \mathrm{m}^{3}$.
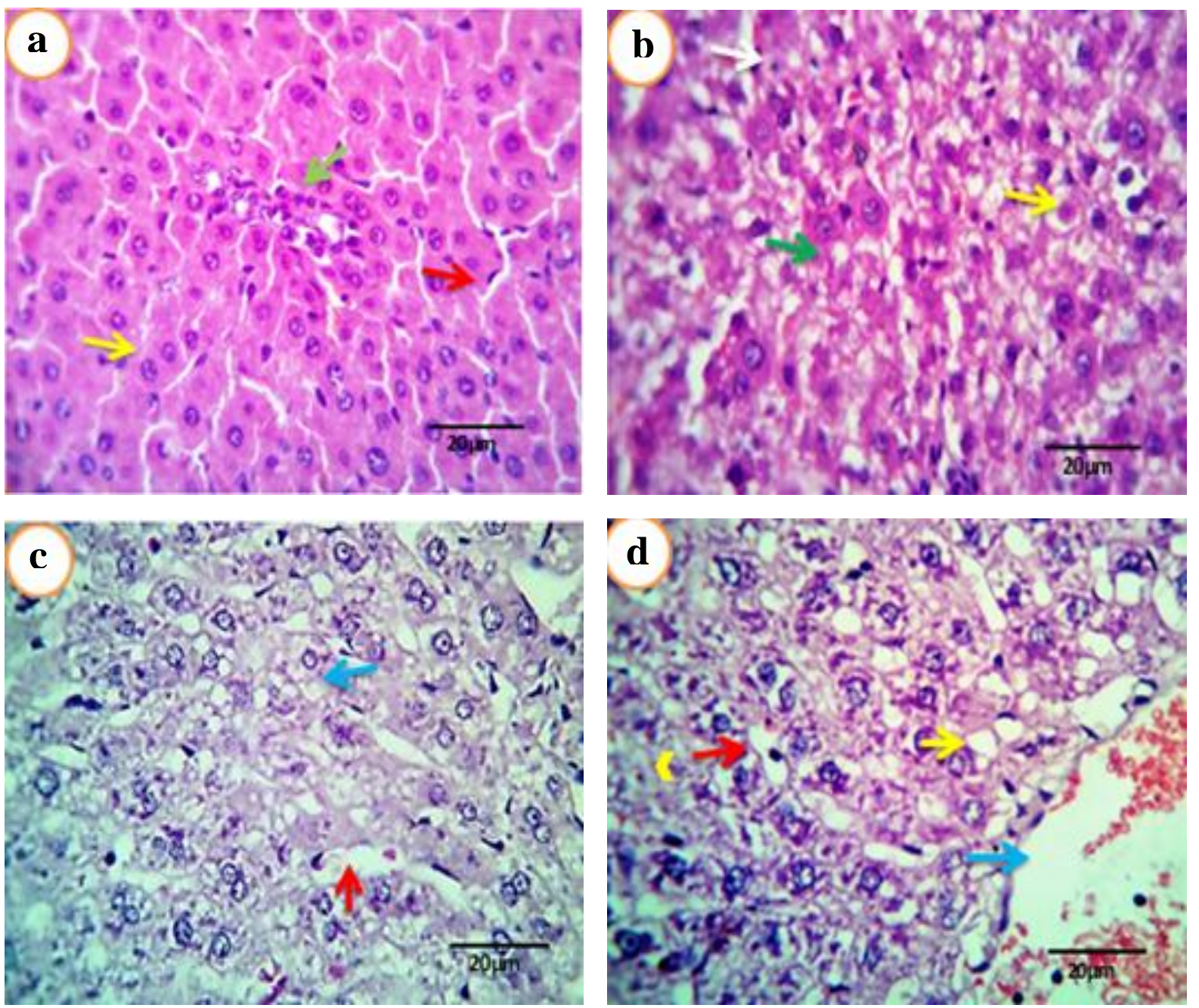

Figure 1: Photomicrograph showing sections of rat liver stained with hematoxylin and eosin (scale bar $=20 \mathrm{um}$ ): (a) control group showing normal hepatic parenchyma with preserved lobular pattern, portal triad structures and central veins (green arrow), sinusoids and hepatic cords (red and yellow arrows), (b) liver tissue of rat exposed to mosquito coil smoke for 3 weeks showing a marked degenerative changes in hepatocytes (cloudy swelling, hydropic degeneration, and/or vacuolations; green arrow) beside apoptotic and early necrotic changes in a variable number of cells (yellow and white arrows), (c) liver tissue of rat exposed to mosquito coil smoke for 6 weeks showing portal vascular and sinusoidal dilatation (red arrow), the hepatocytes shows marked degenerative and early necrotic changes beside fatty steatosis (blue arrow), (d) liver tissue of rat exposed to mosquito coil smoke for 12 weeks showing vascular and sinusoidal dilatation (blue and red arrows), beside characteristic hepatocellular hydropic degeneration, steatosis (yellow arrow), and early necrosis (yellow arrow head). 
The PAHs are associated with PM during burning due to their non-volatile and semi-volatile nature. PAHs concentrations in the emissions in this work ranged from 2.57-56.76 $\mu \mathrm{g} / \mathrm{m}^{3}$, these levels were much higher than the WHO reference limit value "1.2 ng/m". The results of our study were comparable with those reported by Dubey et $a l .{ }^{[7]}$ who stated that PAHs levels in the emissions ranged from 4.0-127.1 $\mu \mathrm{g} / \mathrm{m}^{3}$ for the tested MCs. Benzo[a]pyrene, which is known to be the most human carcinogenic compound of PAHs, has been found in this study to have average concentrations between 2.87-6.15 $\mu \mathrm{g} / \mathrm{m}^{3}$. These concentrations exceeded the State Environmental Protection Administration (SEPA) of China mean-standard value for benzo $[a]$ pyrene in air, which is considered $1.0 \mathrm{ng} / \mathrm{m}^{3}$ for total $\mathrm{PAHs}^{[23]}$. The highest concentration of PM and its content of PAHs detected in this study may be due to carbon powder, wooden powder, and corn starch that being the base materials for the used MC as they represent 64,25 , and $9.4 \%$, respectively, of its total weight.

The high concentrations of PAHs, in particular benzo $[a]$ pyrene detected in the current study, were predicted to be a major reason for health risks in the exposed animals. Due to the role of liver in the metabolism of environmental xenobiotics, it is particularly susceptible to injury. When liver cell membrane is impaired, various enzymes located in the cytosol are released into the bloodstream, thus raising the levels of such enzymes in the blood. The assessment of AST, ALT, and ALP activities in serum was found to be an important tool for evaluating the effectiveness of the liver ${ }^{[24]}$. As seen in Table "1", the activities of AST, ALT, and ALP increased significantly in the sera of all MC smoke exposed groups when compared with the control group, this elevation increased with the duration of exposure. In the presents study, the high activities of such enzymes, especially ALT, may indicate hepatic dysfunction or damage due the toxic effects of PAHs on the membrane phospholipids that increase membrane permeability and escape of these enzymes from liver. It could also be a result of necrotic damages in the hepatocytes ${ }^{[25]}$. Our findings were in agreement with Abubakar and Hassan ${ }^{[26]}$ who stated significant elevation in serum AST, ALT, and ALP activities as a result of exposure to different brands of MC smoke for 8 hours daily for 14 days. In addition, Offor ${ }^{[27]}$ suggested that there were duration-dependent significant elevations of hepatic enzymes in rats exposed to MC smoke for 6, 10, and 14 hours for two weeks. However, benzo $[a]$ pyrene administration according to Kolade and Oladiji ${ }^{[28]}$ caused markedly increases in the activities of blood ALT, ALP, and AST.

The significant increase in total protein levels after inhalation exposure to $\mathrm{MC}$ smoke in the present work may be due to the inflammation resulting from damaged liver cells in response to exposure to irritants released from MC smoke, which may cause loss of plasma fluid into tissues, as mentioned previously by Abubakar and Hassan ${ }^{[26]}$ and Idowu et al. ${ }^{[29]}$. However, the high concentrations of cholesterol, TG, and LDL were reported previously by Abdulla Al-Mamun et $a l_{.}^{[30]}$ and $\mathrm{Naz}$ et $a .^{[31]}$ in albino mice exposed to different mosquito repellent smoke. As TG was the most sensitive lipid class towards PAHs, Li et $a l^{[32]}$ found that inhalation exposure to benzo $[a]$ pyrene markedly increased TG level; it increased 2.2-fold from $10.2 \%$ to $22.8 \%$. Elevated concentration of LDL with significant increases in cholesterol and TG levels may reflect some cardiovascular risk, as it is known that LDL transports cholesterol from the liver to peripheral tissues.

Histological examination of tissue sections of PAHs-exposed rats showed that the liver had lost its normal architecture when compared with the control group. Marked degenerative and early necrotic changes beside fatty steatosis in hepatocytes, as well as vascular and sinusoidal dilatation, have seen in liver tissues of PAHs-exposed rats (Figure 1). The severity of these changes 
was dependent on the duration of exposure and appeared early after 3 weeks of exposure. These histological changes could be due to the effect of ROS generated during PAHs metabolization. The liver in 7,12dimethylbenz $[a]$ anthracene exposed groups exhibited congestion in the sinusoidal and portal regions, dilatation of the sinusoids, and cholangiohepatitis in the portal region according to Yildirim et al. ${ }^{[33]}$, which were similar to those observed in the current study. Also, Idowu et al. ${ }^{[29]}$ observed extensive intracytoplasmic accumulations and mild hydropic change in the liver of rats exposed to MC smoke for two weeks, while after 12 weeks of exposure intracellular accumulations and severe sinusoidal congestion of liver cells were observed. In the current work, it can be assumed that the detected activities of hepatic enzymes were attributable to damage of hepatocyte membranes caused by PAHs emitted during burning of MC. Histological observations showing degenerative changes in livers of rats exposed to PAHs emitted particles support this inference.

In conclusion, indoor air environment was polluted with very high concentrations of PAHs and PM during the burning of MC. The concentrations of theses air pollutants substantially exceeded the recommended values. Furthermore, the detected significant alteration of biochemical parameters and sever histological changes indicated that inhalation exposure to PAHs caused the damage to the liver of exposed rats. As the indoor air pollution is expected to pose potential risk to humans, thus it is advisable to avoid exposure to these toxic MCs, and other alternative ways such as herbal products and nets should be used.

\section{FUNDING SOURCE DISCLOSURE}

This research received no specific grant from any funding agency in the public, commercial, or not-for-profit sectors.

\section{CONFLICT OF INTEREST}

The authors declare no conflict of interest.

\section{AUTHORS' CONTRIBUTIONS}

SEN conceived and designed the experiment, performed the experiment, and discussed results. EIMI designed the experiment, performed the biochemical and statistical analysis, and summarized results.

\section{REFERENCES}

[1] Mulla, M. S.; Thavara, U.; Tawatsin, A. et al. (2001). Mosquito burden and impact on the poor: measures and costs for personal protection in some communities in Thailand. J Am Mosq Control Assoc, 17(3): 153-159.

[2] Ogoma, S. B.; Moore, S. J. and Maia, M. F. (2012). A systematic review of mosquito coils and passive emanators: defining recommendations for spatial repellency testing methodologies. Parasites \& Vectors, 5: 287 (DOI: 10.1186/1756-3305-5-287).

[3] Wang, L.; Zheng, X.; Stevanovic, S. et al. (2018). Characterizing pollutant emissions from mosquito repellents incenses and implications in risk assessment of human health. Chemosphere, 191: 962-970.

[4] Chen, S.-C.; Wong, R.-H.; Shiu, L.-J. et al. (2008). Exposure to mosquito coil smoke may be a risk factor for lung cancer in Taiwan. J Epidemiol, 18: 19-25.

[5] Lukwa, N. and Chandiwana, S. K. (1998). Efficacy of mosquito coils containing $0.3 \%$ and $0.4 \%$ pyrenthrins against An. gambiae sensu lola mosquitoes. Cent Afr J Med, 44(4): 104-107.

[6] Lin, J.-M. and Lee, J.-K. (1997). Vapor phase and particulate bound polycyclic aromatic hydrocarbons in the smoke of mosquito coils. Bull Environ Contam Toxicol, 59: 868-874.

[7] Dubey, J.; Banerjee, A.; Meena, R. K. et al. (2014).Characterization of polycyclic aromatic hydrocarbons in emissions of different mosquito coils. Bull Environ Contam Toxicol, 92: 650-654. 
[8] Kasumba, J.; Hettick, B.; French, A. et al. (2016). Analysis of pesticides and toxic heavy metals contained in mosquito coils. Bull Environ Contam Toxicol, 97: 614-618.

[9] Fagbule, D. and Ekanem, E. E. (1994). Some environmental risk factors for childhood asthma: a case-control study. Ann Trop Paediatr, 14: 15-19.

[10] Ramesh, A.; Inyang, F.; Hood, D. B. et al. (2001). Metabolism, bioavailability, and toxicokinetics of benzo $(\alpha)$ pyrene in F-344 rats following oral administration. Exp Toxicol Pathol, 53(4): 275-290.

[11] Ramesh, A.; Hood, D. B.; Inyang, F. et al. (2002). Comparative metabolism, bioavailability, and toxicokinetics of benzo[ $[a]$ pyrene in rats after acute oral, inhalation, and intravenous administration. Polycycl Aromat Comp, 22(3-4): 969-980.

[12] Sanderson, E. G. and Farant, J. P. (2000). Use of benzo[a]pyrene relative abundance ratios to assess exposure to polycyclic aromatic hydrocarbons in the ambient atmosphere in the vicinity of a Söderberg aluminum smelter. J Air Waste Manage Assoc, 50(12): 2085-2092.

[13] Reitman, S. and Frankel, S. (1957). A colorimetric method for the determination of serum glutamic oxalacetic and glutamic pyruvic transaminases. Am J Clin Pathol, 28: 56-63.

[14] Tietz, N. (1996). Liver Function Tests, Nitrogen Metabolites and Renal Function. In: Fundamentals of Clinical Chemistry (Tietz, N., ed), pp. 476-576. W. B. Saunders Co., Philadelphia, PA, USA.

[15] Doumas, B. T.; Bayse, D. D.; Carter, R. J. et al. (1981). A candidate reference method for determination of total protein in serum. 1. Development and validation. Clin Chem, 27(10): 1642-1650.

[16] Fossati, P. and Prencips, L. (1982). Serum triglycerides determined colorimetically with an enzyme that produces peroxide. Clin Chem, 28(10): 2077-2080.

[17] Artiss, J. D. and Zak, B. (1997). Measurement of Cholesterol Concentration. In: Handbook of Lipoprotein Testing (Rifai, N.; Warnick, G. R. and Dominiczak, M. H., eds), pp. 99-114. AACC Press, Washington, DC, USA.

[18] Wieland, H. and Seidel, D. (1983). A simple specific method for precipitation of low density lipoproteins. J Lipid Res, 24(7): 904909.

[19] Kim Suvarna, S.; Layton, C. and Bancroft J. D. (2013). Bancroft's Theory and Practice of Histological Techniques. Churchill Livingstone Elsevier, London, UK.

[20] World Health Organization (2010). WHO Guidelines for Indoor Air Quality: Selected Pollutants. WHO Regional Office for Europe, Copenhagen, Denmark (https://www. euro.who.int/en/health-topics/environ ment-and-health/air-quality/publicatio ns/2010/who-guidelines-for-indoor-air -quality-selected-pollutants).

[21] Lee, S. C. and Wang, B. (2006) Characteristics of emissions of air pollutants from mosquito coils and candles burning in a large environmental chamber. Atmos Environ, 40(12): 2128-2138.

[22] Liu, W.; Zhang, J.; Hashim, J. H. et al. (2003). Mosquito coil emissions and health implications. Environ Health Perspect, 111(12): 1454-1460.

[23] GB/T 18883-2002 (2002). Indoor Air Quality Standard. Standards Press of China, Beijing, China.

[24] Porchezhian, E. and Ansari, S. H. (2005). Hepatoprotective activity of Abution indicum on experimental liver damage in rats. Phytomedicine, 12(12): 62-64.

[25] Ujowundu, C. O.; Nwokedinobi, N.; Kalu, F. N. et al. (2011). Chemoprotective potentials of Ocimum 
gratissimum in diesel petroleum induced hepatotoxicity in albino Wistar rats. J Appl Pharm Sci, 01(10): 56-61.

[26] Abubakar, M. and Hassan, L. (2006). Toxicological effects of some mosquito coils brands in experimental rats. The Internet Journal of Toxicology, 4(1): 1-4.

[27] Offor, C. E. (2014). Effect of smoke from mosquito coil on serum aspartate transaminase, alanine transaminase and alkaline phosphatase activities in male albino rats. Int $\mathbf{J}$ Curr Res Aca Rev, 2(12): 97-100.

[28] Kolade, O. Y. and Oladiji, T. A. (2019). Protective effects of curcumin against benzopyrene induced liver toxicity in albino rats. IOP Conf Ser: Earth Environ Sci, 210: 012013 (DOI:10.1088/1755-1315/210/ 1/012013).

[29] Idowu, E. T.; Aimufua, O. J.; Ejovwoke, Y.-O. et al. (2013). Toxicological effects of prolonged and intense use of mosquito coil emission in rats and its implications on malaria control. Rev Biol Trop, 61(3): 14631473.
[30] Abdulla Al-Mamun, M.; Ataur Rahman, M.; Habibur Rahman, M. et al. (2017). Biochemical and histological alterations induced by the smoke of allethrin based mosquito coil on mice model. BMC Clin Pathol, 17: 19 (DOI: 0.1186/s12907-0170057-9).

[31] Naz, M.; Rehman, N.; Ansari, M. N. et al. (2019). Comparative study of subchronic toxicities of mosquito repellents (coils, mats and liquids) on vital organs in Swiss albino mice. Saudi Pharm J, 27(3): 348-353.

[32] Li, F.; Xiang, B.; Jin, Y. et al. (2020). Hepatotoxic effects of inhalation exposure to polycyclic aromatic hydrocarbons on lipid metabolism of C57BL/6 mice. Environ Int, 134: 105000 (DOI: 10.1016/j.envint. 2019.105000).

[33] Yildirim, S. S.; Ekin, S.; Huyut, Z. et al. (2018). Effect of chronic exposure to sodium fluoride and 7,12-dimethylbenz[ $a]$ anthracene on some blood parameters and hepatic, renal, and cardiac histopathology in rats. Fluoride, 51(3): 278-290.

\section{How to cite this article:}

Nassar, S. E. and Ismail, E. I. M. (2021). Emission of polycyclic aromatic hydrocarbons in indoor air during burning of mosquito coils and their impacts on the livers of the exposed albino rats. Egyptian Journal of Zoology, 76: 1-11 (DOI: 10.12816/ejz.2021.66257.1050). 


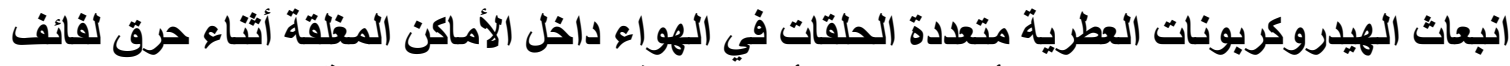

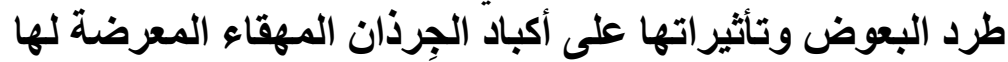

\section{صفاء عزت نصار 1، إيمان إسماعيل محمد إسماعيل2 2}

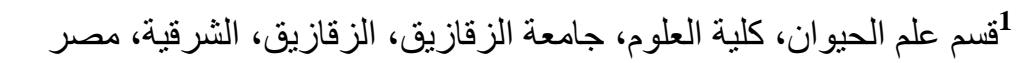

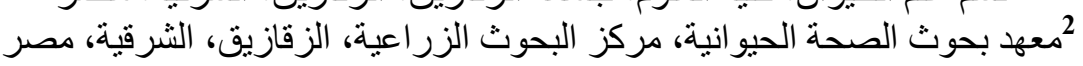

ينتج عن حرق لفائف طرد البعوض داخل المنازل انبعاث جسيمات وهيدروكربونات عطرية متعددة الحلقات

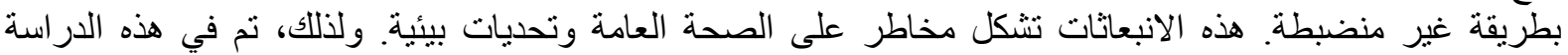

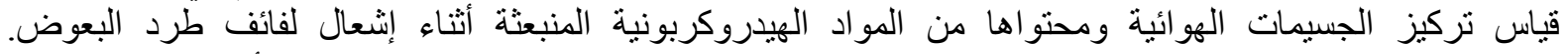

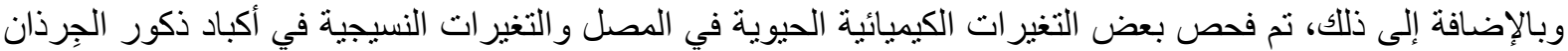

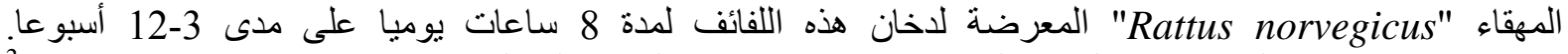

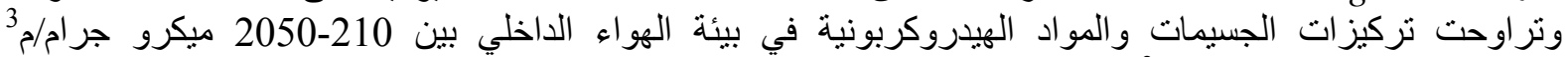

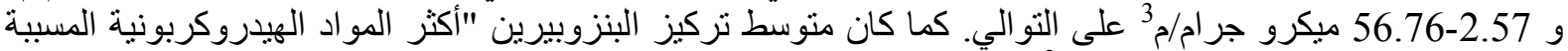

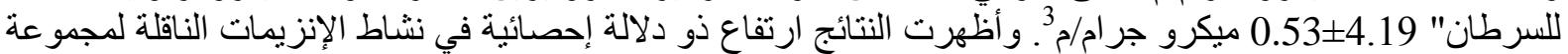

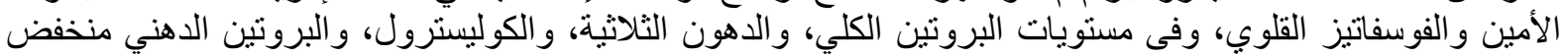

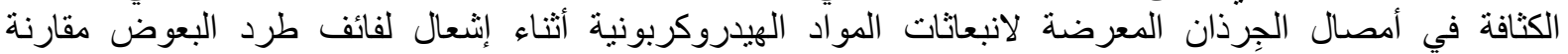

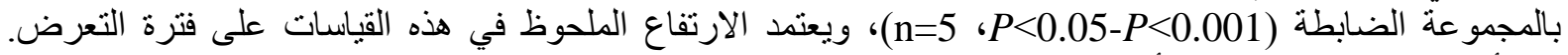

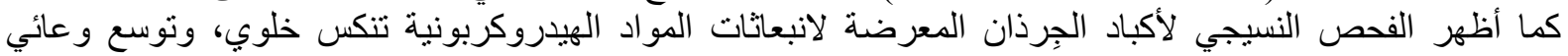

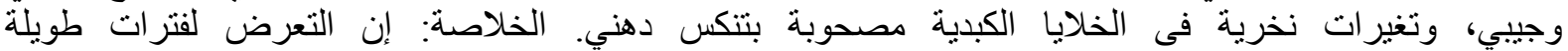

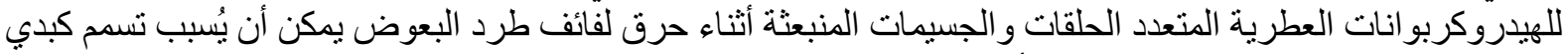

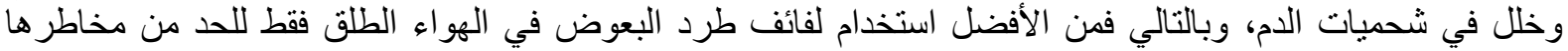
الصحية على المتو اجدين داخل المباني. 